\title{
ASSOCIATION OF HBA1C AND NEUTROPHIL LYMPHOCYTE RATIO WITH NORMAL- TENSION GLAUCOMA IN METABOLIC SYNDROME AND OBSTRUCTIVE SLEEP APNEA RISK PATIENTS
}

\author{
Seskoati Prayitnaningsih ${ }^{1}$, Virna Oktarina Asrory ${ }^{2}$, Synthia Nusanti $^{3}$, Erlin Listyaningsih ${ }^{4}$ Bambang Budi Siswanto ${ }^{5}$, Anwar \\ Santoso ${ }^{6}$. \\ Correspondence: seskoatip@yahoo.com \\ ${ }^{1}$ Department of Ophthalmology, Faculty of Medicine, University of Brawijaya, Malang 65145, Indonesia, \\ ${ }^{2}$ Department of Ophthalmology, Faculty of Medicine, University of Indonesia, Jakarta 10430, Indonesia, \\ ${ }^{3}$ Harapan Kita Nasional Cardiovarcular Center, Jakarta 11420, Indonesia \\ ${ }^{4}$ Department of Ophthalmology, Faculty of Medicine, University of Indonesia, Jakarta 10430, Indonesia, \\ ${ }^{5}$ Department of Cardiology, Faculty of Medicine, University of Indonesia, Jakarta 10430, Indonesia, \\ ${ }^{6}$ Department of Cardiology, Faculty of Medicine, Universit of Indonesia, Jakarta 10430, Indonesia
}

Article History:

Received April 30, 2021

Accepted: June 30, 2021

Published: July 1, 2021

\section{Cite this as:}

Prayitnaningsih S, Asrory VO,

Nusanti S, Listyaningsih E,

Siswanto BB, Santoso A.

Association of hbalc and

neutrophil lymphocyte ratio with

normal-tension glaucoma in

metabolic syndrome and

obstructive sleep apnea risk

patients. Malang Neurology

Journal; 2021.7: 149-155.

http://dx.doi.org/10.21776/ub.mnj

2021.007 .02 .14

\section{ABSTRACT}

Background: Normal-Tension Glaucoma (NTG) is an eye disease and characterize with low intraocular pressure (IOP) levels. In population-based settings, the diagnose of glaucoma is based on the IOP levels of $21 \mathrm{mmHg}$, and its usually delayed. A recent study HbA1c levels could lead to IOP changes. Obstructive Sleep Apnea (OSA) result oxidative stress that results an altered function of neutrophil in patients with NTG.

Objective: To evaluate the association of HbAlc, Netrophil-to-Lymphocyte Ratio (NLR) toward NTG as its novel early detection.

Methods: This study divided into two groups consisted of Metabolic Syndrome ( MS) + OSA without eye disorder as control (15 subjects) and MS + OSA + NTG patients (14 subjects). IDF criteria was used to established MS, and risk of OSA determined by STOP-BANG Questionnaire. The diagnosis of NTG was confirmed by normal IOP measured by Tonopen. Mean Defect (MD) of visual field evaluated by Automated Humphrey Perimetry, Retinal Nerve Fiber Layer (RNFL) established by OCT. HbA1c measured by ELISA and NLR by flowcytometry. Statistical analysis consisted of comparison and correlation test

Results: The ratio of CD was significantly higher in NTG patients $(0.54 \pm 0.13)$ compared to control $(0.26 \pm 0.07 ; \mathrm{p}<0.001)$. MD was also higher in subjects with NTG $(6.80 \pm 3.90)$ compared to control $(4.97 \pm 2.28 ; \mathrm{p}=0.134)$. Mean RNFL was lower in subjects with NTG $(87.95 \pm 28.29)$ compared to control $(95.07 \pm 26.66 ; p=0.035)$. Positive correlation between HbA1C-MD $(r=0.456, p=0.013)$ and NLR-RNFL thinning $(r=0.525, \mathrm{p}=0.003)$ was existed in Metabolic Syndrome (MS) patients.

Conclusion: Patients with MS and OSA risk have an increased risk of NTG. A novel association between Hba1C levels, NLR and NTG was also identified.

Keywords: HbA1c, normal-tension glaucoma, neutrophil-lymphocyte ratio, metabolic syndrome

\section{Introduction}

Body Vision 2020 estimated about 45 million people worldwide are blind. ${ }^{1}$ mostly are caused by the diseases, treatable or preventable. Eighty percent are from the developing countries. Without intervention, the number of blindness might reach 76 million cases by 2020 , caused by several factors, mainly the rapid aging of populations. ${ }^{2}$ Since the eye disease is largely affecting older people, the number of blindness and low vision in people older than 50 years is estimated increase to 2 billion by 2020. The specific target of VISION 2020 are being developed, including the diabetic retinopathy, glaucoma, cataract, occupational eye injury, refractive error and low vision, vision rehabilitation, childhood screening and treatment. ${ }^{1}$
According to WHO 2010, cataract is the leading of blindness, followed by glaucoma and age - related macular degeneration (ARMD). Glaucoma is an optic neuropathy disease with cupping of optic nerve head along with narrowing visual field leading to blindness. Current therapy which attempts to lower the intra-ocular pressure (IOP) has not capable to stop the optic neuropathy glaucoma progression. This phenomena resulted in a lot of study to interfere the advancement of neuropathy optic glaucoma (NOG), including Obstructive Sleep Apnea Syndrome (OSAS) and metabolic syndrome (MS) role in the progression of NOG. A wide range prevalence in Indonesia of glaucoma with OSAS was $2,2 \%$ to $57 \%$. OSAS increased the risk of Normal-Tension Glaucoma (NTG) up 
to 4 times. Vascular insufficiency caused by lowering ocular blood flow, vascular dysregulation, or increasing trans-lamina cribosa pressure resulted in Retinal Ganglion Cell (RGC) death, mainly in NTG patient. ${ }^{3}$

Normal-tension glaucoma (NTG), a subset of open - angle glaucoma (OAG), is a progressive glaucomatous optic neuropathy and causing visual field defects, but it have an normal intraocular pressure (IOP). ${ }^{4}$ NTG patients generally have vascular abnormalities such as vasospasms leading to ischemia. It is thought to have an important role in the NTG pathogenesis. ${ }^{5}$ Disc hemorrhage is frequently observed in NTG than in high-tension glaucoma patients. This event is suggested to be the consequence of the disturbances of hemodynamic, including micro-infarction in the optic nerve head ${ }^{6}$; retinal circulation disorder $^{7}$; capillary perfusion reduction $^{8}$; and primary vascular dysregulation. ${ }^{9}$

Metabolic syndrome consists of several factors such as impaired glucose tolerance (IGT), hyperlipidemia, hypertension and obesity. ${ }^{10}$ This may lead to a rife microvascular dysfunction and hemodynamic disturbance. ${ }^{11-12}$ Conflicts regarding the correlation between any of the many components of the metabolic syndrome and the risk of having OAG have been proven in previous studies. In spite of glaucoma is a multifactorial disease, increased intraocular pressure (IOP) still its major known risk factor, but the pathogenesis remain unclear. ${ }^{13}$ Several large randomized clinical trials stated that there is a relationship between IOP and the development and progression of glaucoma. ${ }^{14}$ Therefore, an adequate determination of IOP is the most importance in the management of the disease.

Hypoxia or recurrent re-oxygenation process in OSA result in the emergence of oxidative stress that will activate and accelerate peroxidation damage and inflammation. Some subcellular parts that involved in ROS production are mitochondria, reticulum endoplasma, cellular membrane, lysosom, peroxisome, and enzymatic system. Enzymatic components which takes part are NADPH oxydase (Nox2 and Nox4), Xanthine Oxidase (XOD), phospholipase A2, lipoxygenase, cyclooxigenase, and uncoupled nitric oxide synthase (NOSs). As the consequence, tissue and cellular damage, endothelial disfunction, and metabolic disturbance will occur. A couple of comorbids such as Type 2 Diabetes Mellitus, dyslipidemia, cardiovascular complication, and declined neuro cognitive function will take place. ${ }^{15}$ NOG multiplies by 4 times in OSAS patient, and AHI significantly correlated with CD ratio. ${ }^{16}$

The IOP value is influenced by several systemic factors such as hypertension ${ }^{17}$, atherosclerotic diseases ${ }^{18}$, body mass index ${ }^{19}$, and diabetes. ${ }^{20}$ Lee and colleagues investigating the relationship between IOP and systemic disorders stated that an increase in mean blood pressure is strongly correlated with an increase risk of IOP. Although in most population studies stated that diabetes is associated with higher IOP, the underlying mechanisms remains unclear. ${ }^{21}$ Recent studies suggested that changes in corneal biomechanics (increased corneal hysteresis) in diabetic eye lead to an overestimated IOP values. ${ }^{21}$ But, if the variation of glucose levels and HbA1c can lead to variability of IOP in patients with diabetes and nondiabetes is still unknown. As diabetes and glaucoma (or ocular hypertension) coexists in patients, a better understanding about the variations in glucose levels and HbA1c influence IOP would provide information to the IOP assessment in NTG patient.

Normal-tension glaucoma (NTG) is characterizing by the low level of intraocular pressure (IOP) and preserves its importance for public health care. In population-based study, the diagnosis and management is usually delayed. ${ }^{22}$ NTG is associated with some autoimmune and systemic diseases, such as paraproteinemia, nocturnal hypotension, and migraine. Recently, a simple test (the hemogram) was defined to measure systemic inflammation, identifying the neutrophil-to-lymphocyte ratio (NLR). A recent study shows an altered neutrophil function in NTG patients. We hypothesize that the analysis for NLR and IOP together may used to diagnose NTG in primary care clinics, if there is an association between NTG and NLR demonstrated in future researches. ${ }^{23}$ According Vision 2020 and Indonesian Ministry of Health 2019 policy to decrease almost 25\% prevalence of visual defect so we do this research aimed to evaluate the association of HbA1c, NLR toward NTG as its novel early detection in patient with metabolic syndrome and has OSAS risk.

\section{Methods And Materials}

\section{The Patients}

This research was conducted under complete ethical clearance of "National Cardiac Center Harapan Kita Hospital" (LB.02.01/VII/287/KEP.054/2018). All of the patients participating in this study who were under 40 years had an informed consent letter signed voluntarily. From 800 patients with metabolic syndrome (MS), it was selected 15 patients MS + Obstructive Sleep Apnea (OSA) + Normaltension Glaucoma (NTG) and 14 patients MS + OSA without eye disorder (Slit Lamp SL 220). Patients were confirmed MS (waist measurement, systolic blood pressure, fasting blood glucose, triglyceride, and HDL) and OSA from STOP-BANG questionnaire (sensitivity 83,6\%, specificity 56,4\%). ${ }^{24}$ Finally, 15 selected patients with glaucoma and normal IOP were studied, compared to 14 patients in the control group (MS + OSA patients).

\section{Obstructive Sleep Apnea}

STOP-BANG Questionnaire was used as an instrument to measure the risk OSA as Apnea-Hypopnea Index (AHI). ${ }^{25}$

\section{Metabolic Syndrome}

Metabolic syndrome was characterized as central obesity along with 2 of 4 IDF Criteria 2006 from physical and blood chemical analysis. ${ }^{26}$ Physical examination covered central obesity sign (circumference of waist (men: $>90 \mathrm{~cm}$; women: $>80 \mathrm{~cm}$ ) and elevated systolic blood pressure (SBP) $>130 \mathrm{mmHg}$ or under anti-hypertensive drug therapy. Blood chemical analysis characteristic was determined from elevated fasting blood glucose $(>100$ $\mathrm{mg} / \mathrm{dL}$ ) or currently treated with anti-diabetic agent, elevated TG (>150 mg/dL) or receiving anti-dyslipidemic drug, and low HDL (<40 mg/dL).

\section{Neutrophil-Lymphocyte Ratio (NLR) and HbA1c Measurement}

Whole blood from patients were collected and analyzed its NLR on Sysmex XN 2000 and HbA1c was measured by Roche Cobas C 311 analyzer. 


\section{Normal-tension Glaucoma}

Patients participated in this study were confirmed having normal IOP by tonopen (ICare Pro). Furthermore, perimetry (HFA 3 type 860) was performed to analyze mean defect in visual field loss. Then, RNFL was examined by Optical Coherence Tomography (CIRRUS HD OCT 5000). The CD ratio was measured using Wide Lens Super Field 90D. Finally, patients' eyes were examined by goniolense (Slit lamp SL 220) to determine the angle.

\section{Statistical Analysis}

Data gathered were analyzed by correlative statistics (Pearson, Spearman, Correlation test) and comparative statistics (T-test) using IBM SPSS Statistics ver. 21 software.

\section{Results}

\section{Subject Characteristics}

Among 240 participants in this study who have MS, 29 patients were completely underwent ophthalmology examination. The data of demographic and clinical are presented in Table 1. No significant difference of age between patient with NTG (49.60 \pm 12.55 years) and without NTG $(50.64 \pm 5.39$ years, $\mathrm{p}=0.776)$. The female proportion was not significantly different between patients with NTG (60\%) and without NTG (64.9\%; p = 0.972). Patients with NTG were insignificantly tended to have higher fasting glucose (99.33 vs $96.89 \mathrm{mg} / \mathrm{dl} ; \mathrm{p}=0.615)$ and higher triglyceride (181.07 vs $152.93 \mathrm{mg} / \mathrm{dl} ; \mathrm{p}=0.777$ ) compared to patients without NTG. Both groups had almost no different mean value of BMI (29.29 vs 30.96; $\mathrm{p}=0.341)$, waist circumference $(95,33$ vs 95,$79 ; \mathrm{p}=0.484)$, and HDL (44.80 vs 43.07; $\mathrm{p}=0.529$ ). The questionnaire of STOPBANG was used to determine the OSA risk in MS patients. This examination result was compared in NTG and nonNTG subjects. The STOP-BANG score showed no marked difference $(\mathrm{p}=0.824)$ between NTG $(40 \%$ subjects had low mild risk, $46,67 \%$ subjects had moderate risk, and $13,33 \%$ subjects had severe risk) and non-NTG $(35,71 \%$ subjects had low mild risk, 64,29\% subjects had moderate risk, and no subjects possessed severe risk) subjects (Table 1).

\section{Ocular Examination}

Mean CD ratio was significantly higher in subjects with NTG $(0.54 \pm 0.13)$ compared to non-NTG subjects $(0.26 \pm$ $0.07 ; \mathrm{p}<0.001)$. Mean defect was also higher in subjects with NTG $(6.80 \pm 3.90)$ compared to subjects without NTG $(4.97 \pm 2.28 ; \mathrm{p}=0.134)$ even though not statistically significant. Mean RNFL was lower in subjects with NTG $(87.95 \pm 28.29)$ than the non-NTG subjects $(95.07 \pm 26.66$; $\mathrm{p}=0.035)$ (Table 2).

\section{Association of Metabolic Syndrome parameters, HbA1C, and NLR to normal-tension glaucoma parameters}

Positive correlation existed between $\mathrm{HbA1C}$ and Mean Defect value in patients with MS $(r=0.456 ; p=0.013)$. There is a positive significant correlation between NLR and RNFL in patients with MS $(r=0.525 ; \mathrm{p}=0.003)$. No significant correlation between any parameters of MS and either mean defect, RNFL or CD ratio in all of the subjects participated.

\section{Discussion}

This research was conduct to determine the association between NTG and metabolic syndrome-OSA risk patient and to analyze the association of HbA1c, NLR toward NTG as NTG novel predictive detection. It has demonstrated that metabolic syndrome component and OSA risk factor were associated but not significantly with prevalence of NTG. The Singapore Malay Eye Study stated that the NTG prevalence had a U-shaped relationship with metabolic abnormalities. ${ }^{27}$ The difference in NTG prevalence could be explained by the age difference of study populations.

Recent study shows that IGT is correlated with NTG. This event corresponds with latest studies that diabetes contributes to an increased risk of glaucoma development. $^{28,29,30,31,32,33}$ Another research shows that impaired auto regulation is an important mechanism for glaucoma development. ${ }^{34,35,36}$ Therefore, hypothesizing that diabetes may be correlated with glaucoma is reasonable. In the other hand, there are some studies which showed no significant association between glaucoma and diabetes. ${ }^{37,38}$ Despite the fact that patients referred for an ophthalmological examination have diabetes, it has not known yet whether blood glucose levels could influence an individual IOP variation till present. This study is the first report providing evidence that Hbalc is significantly associated with NTG (Mean Defect). We identified an association between Hba1c and NTG that may help to understand the inconsistent of previous findings about the relationship of diabetes or metabolic syndrome in increased glaucoma risk. This study has a significant implication for the public health program and may guide the direction of further researches.

We found a positive and significant correlations between HbA1c-Mean Defect $(r=0.456 ; p=0.013)$ in NTG patients, which partly can be explained by Hba1c level magnitude variation in patients. A recent meta-analysis stated that diabetes, duration of diabetes, and the level of fasting glucose were all correlated with an increased risk of glaucoma. The history of diabetes was reported to be a protective factor against the NTG development. ${ }^{39}$ Another potential mechanisms including hyperglycemia, leading to the dysfunction of trabecular meshwork, the gradient osmotic changes related to the dysregulation of autonomic, or microvascular disorder of the retina or the optic nerve [40]. Interestingly, a single-variable analysis shows that the duration of diabetes is associated with the risk of glaucoma compared to patients without diabetes. This phenomena may occur due to the effect of survivort - defined as people with diabetes with longer duration mainly have comorbidities which lower the the quality of their fundus imaging and prevented the grading.

Our research also proved the predictive role of NLR in NTG. We found a positive significant correlation between NLR and NTG (RNFL parameter) in patients with MS ( $\mathrm{r}=$ $0.525 ; p=0.003)$. The evaluation studies of the NTG pathogenesis reveals several potential risk factors such as nocturnal hypotension, inflammatory diseases, migraine, circulating retina and optic nerve auto-antibodies, and an altered C-reactive protein (CRP). ${ }^{41,42}$ Normally, systemic blood pressure decreases in night time, but show more substantial decrement in some patients, called "dipper". 
Recent studies have shown a higher NLR in non-dipper patients. ${ }^{43}$ Another study stated that non-dipper patients have an increased of platelet activation and response of inflammatory. ${ }^{44}$ The non - dipper patients are unlike the patients of nocturnal hypotensive regarding their systemic blood pressure. However, association between systemic blood pressure and NLR play an important role in NTG. The dysregulation of systemic vascular is also noted as a common mechanism in migraine and NTG caused by and endothelial dysfunction and vasospasm. ${ }^{45,46}$ Several research also showed that platelets and NLR have a significant role in migraine episodes. ${ }^{47,48}$

A new evidence associate with the host immune role response with the NTG pathogenesis. ${ }^{49,50,51}$ The concept in the NTG development firstly from an medical examination where one or more diseases related to immune found in
$30 \%$ of NTG patients. ${ }^{42}$ The importance of autoimmunity in NTG then shows by the increased level of auto-antibodies likes anti-rhodopsin and anti-gluthatione $\mathrm{S}$ transferase. ${ }^{52,53}$ Wax et al. reported an increased incidence of serum autoantibodies and paraproteinemia in NTG patients. ${ }^{53}$ In addition, $\operatorname{IgA}$ and $\operatorname{IgG}$ deposition, along with the ganglion cells apoptosis and other inner nuclear retinal layer cells was observed. ${ }^{54}$ There is a response of systemic immune cell for the auto antibodies synthesis. However, the importance of pro-inflammatory level in serum of NTG must be further examined. Finally, the specific autoantibodies detection for the diagnosis and early detection of glaucoma requires a relatively high cost. The limitation of study is due to a relatively small sample size and the diagnosis of OSA risk wasn't determined by quantitative measurement instrument.

Table 1. The characteristics of study population with and without normal - tension glaucoma

\begin{tabular}{|c|c|c|c|c|}
\hline Characteristics & All Subjects & Subjects without NTG & Subjects with NTG & p-value \\
\hline \multicolumn{5}{|l|}{ Mean $(S D)$} \\
\hline Age, year & $50.10(9.62)$ & $50.64(5.39)$ & $49.60(12.55)$ & 0.776 \\
\hline Systolic BP, mmHg & $132.86(15.72)$ & $136.29(18.25)$ & $129.67(12.75)$ & 0.265 \\
\hline Diastolic BP, mmHg & 78.66 (7.71) & $78.36(5.81)$ & 78.93 (9.34) & 0.677 \\
\hline Fasting Glucose, mg/dl & $98.15(51.16)$ & $96.89(42.47)$ & $99.33(59.65)$ & 0.615 \\
\hline Body Mass Index, $\mathrm{kg} / \mathrm{m}^{2}$ & $30.10(4.63)$ & $30.96(5.27)$ & $29.29(3,96)$ & 0.341 \\
\hline Waist Circumference & $95.55(7.93)$ & 95.79 (7.91) & $95.33(8.21)$ & 0.484 \\
\hline Triglyceride, mg/dl & $167.48(105.72)$ & $152.93(54.36)$ & $181.07(138.56)$ & 0.777 \\
\hline $\mathrm{HDL}, \mathrm{mg} / \mathrm{dl}$ & $43.97(8.47)$ & $43.07(7.98)$ & $44.80(9.10)$ & 0.529 \\
\hline \multicolumn{5}{|l|}{ No $(\%)$} \\
\hline \multicolumn{5}{|l|}{ STOP-Bang Score } \\
\hline $1-2$ (Low mild) & $11(37.93)$ & $5(35.71)$ & $6(40)$ & 0.824 \\
\hline 3-4 (Moderate) & $16(55.17)$ & $9(64.29)$ & $7(46.67)$ & \\
\hline 5-8 (Severe) & $2(6.89)$ & $0(0)$ & $2(13.33)$ & \\
\hline Gender (Female) & $18(62.07)$ & $9(64.29)$ & $9(60)$ & 0.972 \\
\hline
\end{tabular}

Table 2. Comparison between two studied groups according to ocular examination findings.

\begin{tabular}{|c|c|c|c|c|}
\hline Characteristics & All Subjects & Subjects without NTG & Subjects with NTG & p-value \\
\hline \multicolumn{5}{|l|}{ Mean (SD) } \\
\hline IOP, mmHg & $15.36(3.78)$ & $15.82(4.68)$ & $14.90(2.61)$ & 0.763 \\
\hline CD Ratio & $0.40(0.18)$ & $0.26(0.07)$ & $0.54(0.13)$ & $<0.001$ \\
\hline Mean Defect & $5.92(3.30)$ & $4.97(2.28)$ & $6.80(3.90)$ & 0.134 \\
\hline RNFL & $91.39(27.51)$ & $95.07(26.66)$ & $87.95(28.29)$ & 0.035 \\
\hline
\end{tabular}

Table 3. Correlation of Metabolic Syndrome parameters, HbA1C, and NLR to normal-tension glaucoma parameters (bivariate)

\begin{tabular}{|c|c|c|c|c|c|c|}
\hline & \multicolumn{2}{|c|}{ Mean Defect } & \multicolumn{2}{|c|}{ RNFL } & \multicolumn{2}{|c|}{ CD Ratio } \\
\hline & $\mathrm{r}$ & $\mathrm{p}$ & $\mathrm{r}$ & $\mathrm{p}$ & $\mathrm{r}$ & $\mathrm{p}$ \\
\hline Systolic BP, mmHg & -0.001 & 0.995 & 0.078 & 0.688 & -0.361 & 0.054 \\
\hline Diastolic BP, mmHg & -0.010 & 0.958 & -0.061 & 0.752 & -0.131 & 0.499 \\
\hline Fasting Glucose, mg/dl & -0.042 & 0.828 & 0.392 & 0.035 & 0.156 & 0.420 \\
\hline Body Mass Index, $\mathrm{kg} / \mathrm{m}^{2}$ & 0.159 & 0.441 & -0.066 & 0.734 & -0.212 & 0.270 \\
\hline Waist circumference & 0.119 & 0.538 & -0.150 & 0.439 & -0.058 & 0.764 \\
\hline Triglyceride, mg/dl & 0.018 & 0.925 & 0.131 & 0.500 & -0.037 & 0.848 \\
\hline $\mathrm{HbA1C}$ & 0.456 & 0.013 & 0.025 & 0.897 & 0.153 & 0.428 \\
\hline $\begin{array}{l}\text { Neutrophil to Lymphocyte } \\
\text { Ratio }\end{array}$ & -0.268 & 0.160 & 0.525 & 0.003 & -0.005 & 0.979 \\
\hline STOP-Bang Score & -0.015 & 0.939 & 0.357 & 0.057 & 0.096 & 0.619 \\
\hline
\end{tabular}

A single - variable analysis suggests the association of diabetes duration with risk of glaucoma. This phenomena may occur due to the effect of survivor — defined as people with longer duration of diabetes mainly have comorbidities which lower the quality of their imaging of fundus and prevented grading.
A promising new evidence associate with the role of host immune response and the NTG pathogenesis. ${ }^{49-51}$ The concept in the NTG development firstly from an examination, where one or more diseases related to immune were found in $30 \%$ of NTG patients. ${ }^{42}$ 
The importance of autoimmunity was shows by the increased level of auto - antibodies circulating, like antirhodopsin and anti-gluthatione $\mathrm{S}$ transferase. ${ }^{52,53}$ Wax et al. observed IgA and IgG deposition, along with the ganglion cells apoptosis and other inner nuclear retinal layer cells. Furthermore, an increased incidence of serum autoantibodies and paraproteinemia in NTG patients was reported. ${ }^{54}$ There is a response of systemic immune cell for the auto antibodies synthesis. However, the importance of pro-inflammatory level in serum of NTG must be further examined. Finally, the specific auto-antibodies detection for the diagnosis and early detection of glaucoma requires a relatively high cost.. The limitation of this research is due to a small sample size and the diagnosis of OSA risk wasn't determined by quantitative measurement instrument.

\section{Conclusion}

There is an insignificant correlation between SM and OSA risk toward NTG. HbA1c and NLR are two promising candidates to become a novel biomarker for the diagnosis of NTG.

\section{Acknowledgement}

We would like to express our deepest gratitude to Dr. dr. Anwar Santoso, $\operatorname{SpJP}(\mathrm{K}), \quad$ Professor Bambang Budi Siswanto, SpJP, dr. Erlin Listyaningsih, M.Kes our research supervisors, for their patient guidance, enthusiastic encouragement, and useful critiques on this research. We would also like to extend our gratitude to Dr. Syntia, $\operatorname{SpM}(K)$, and Dr. Virna, $\operatorname{SpM}(K)$, for their advice and assistance in ensuring that this study adheres to the predetermined timeline. We would also like to thank the laboratory technicians at National Cardiology Center Harapan Kita, Jakarta, for their help in processing the samples.

It contains the article's support or sponsorship, written using Times New Roman 10 with single space and each new paragraph indents in $3 \mathrm{pt}$.

\section{Conflict of Interest}

The authors have no conflict of interest to declare.

\section{References}

1. Evans K, Holden B, Nicholls C. VISION 2020: The Right to Sight-Australia. N S W Public Health Bull; 2001. 12(1):14-15. DOI : 10.1071/nb01006.

2. Pararajasegaram R. VISION 2020-The Right to Sight: from strategies to action. Am J Ophthal-mol; 1999. 128(3):359-360.

DOI : 10.1016/s0002-9394(99)00251-2.

3. Ahmad, SS. Controversies in the vascular theory of glaucomatous optic nerve degeneration. Taiwan Journal of Ophthalmology; 2016. 6(4): 182-186. DOI : 10.1016/j.tjo.2016.05.009.
4. Shields MB. Normal-tension glaucoma: is it different from primary open-angle glaucoma? Curr Opin Ophthalmol; 2008. 19: $85-88$.

DOI : 10.1097/ICU.0b013e3282f3919b

5. Caprioli_J \& Spaeth GL._Comparison of visual field defects in the low-tension glaucomas with those in the high-tension glaucomas. Am J Ophthalmol; 1984. 97(6): 730-737. DOI : 10.1016/0002-9394(84)905051.

6. Begg IS, Drance SM \& Sweeney VP. Ischaemic optic neuropathy in chronic simple glaucoma. $\mathrm{Br} \mathrm{J}$ Ophthalmol; 1971. 55(2): 73-90.

DOI : $10.1136 /$ bjo.55.2.73.

7. Sonnsjo B \& Krakau CE. Arguments for a vascular glaucoma etiology. Acta Ophthalmol; 1993. 71(4): 433-444. DOI : 10.1111/j.1755-3768.1993.tb04615.x.

8. Kurvinen L, Harju M, Saari J \&Vesti E. Altered temporal peripapillary retinal flow in patients with disc hemorrhages. Graefes Arch Clin Exp Ophthalmol; 2010. 248(12): 1771-1775.

DOI : $10.1007 / \mathrm{s} 00417-010-1441-7$.

9. Grieshaber MC, Mozaffarieh M, Flammer J. What is the link between vascular dysregulation and glaucoma? Surv Ophthalmol; 2007. 52(2):144-154. DOI : 10.1016/j.survophthal.2007.08.010.

10. Iwashima $\mathrm{Y}$, Horio $\mathrm{T}$, Kamide $\mathrm{K}$ et al. Additive interaction of metabolic syndrome and chronic kidney disease_on cardiac hypertrophy,_and risk of cardiovascular disease in hypertension. Am J Hypertens; 2010. 23: 290-298.

DOI : https://doi.org/10.1038/ajh.2009.253

11. Grundy SM. Hypertriglyceridemia, insulin resistance, and the metabolic syndrome. Am J Cardiol; 1999. 83: 25F-29F. DOI : 10.1016/s0002-9149(99)00211-8.

12. Wilson PW, Kannel WB, Silbershatz H \& D'Agostino RB. Clustering of metabolic factors and coronary heart disease. Arch Intern Med; 1999. 159: 11041109. DOI : 10.1001/archinte.159.10.1104

13. Kass MA,_Heuer DK, Higginbotham EJ, et al. The Ocular_Hypertension Treatment_Study : A randomized trial determines that topical ocular hypotensive medication delays or prevents the onset of primary open-angle glaucoma. Archives of Ophthalmology; 2002. 120(6): 701-713.

DOI : 10.1001/archopht.120.6.701

14. Sommer, A J. M. Tielsch, J. Katz et al. Relationship between intraocular pressure and primary open angle glaucoma among white and black Americans: The Baltimore eye survey. Archives of Ophthalmology; 1991. 109(8): 1090-1095.

DOI : 10.1001/archopht.1991.01080080050026

15. Wong WT, Wong WL, Tian XY, Huang Y. Endothelial dysfunction: The common consequence in diabetes and hypertension. J Cardiovasc Pharmacol; 2010. 55(4):300-307.

DOI : 10.1097/fjc.0b013e3181d7671c

16. Karaca EE, Ozmen MC, Ekici F, Yuksel E, Turkoglu Z. Neutrophil-to-lymphocyteratio may predict progression in patients with keratoconus. Cornea; 2014. 33:1168-7.

DOI : $10.1097 /$ ICO.0000000000000260 
17. He Z, Vingrys AJ, Armitage JA, Bui BV. The role of blood pressure in glaucoma. Clin Exp Optom; 2011. 94(2):133-149.

DOI : 10.1111/j.1444-0938.2010.00564.x

18. Lee JS, Lee SH, Oum BS, Chung JS, Cho BM, Hong JW. Relationship between intraocular pressure and systemic health parameters in a Korean population. Clinical \& Experimental Ophthalmology; 2002. 30(4):237-241. DOI : $10.1046 / \mathrm{j} .1442-$ 9071.2002.00527.x

19. Wang YX, Xu L, Zhang XH, You QS, Zhao L, Jonas JB. Five-year change in intraocular pressure associated with changes in arterial blood pressure and body mass index. The Beijing eye study. PLoS ONE; 2013. 8(10):77180.

DOI : https://doi.org/10.1371/journal.pone.0077180

20. Memarzadeh, Ying-Lai M, Azen SP, and Varma R. Associations with intraocular pressure in Latinos: The Los Angeles Latino Eye Study. American Journal of Ophthalmology; 2008. 146(1): 69-76.

DOI : 10.1016/j.ajo.2008.03.015

21. Castro DP, Prata TS, Lima VC, Biteli LG, de Moraes CGV, and Paranhos A. Corneal viscoelasticity differences between diabetic and nondiabetic glaucomatous patients. Journal of Glaucoma; 2010. 19(5):341-343. DOI : 10.1097/ijg.0b013e3181b4caa1

22. Ulu SM, Dogan M, Ahsen A, et al. Neutrophil-tolymphocyte ratio as a quick and reliable predictive marker to diagnose the severity of diabetic retinopathy. Diabetes Technol Ther; 2013. 15:942-7. DOI : 10.1089/dia.2013.0097

23. Karaca EE, Ozmen MC, Ekici F, Yuksel E, Turkoglu Z. Neutrophil-to-lymphocyte ratio may predict progression in patients with keratoconus. Cornea; 2014. 33:1168-73.

DOI : 10.1097/ICO.0000000000000260

24. Duarte, RL de M, Fonseca, LB de M, Magalhães-daSilveira, FJ, Silveira, EA da, \& Rabahi, MF. Validation of the STOP - Bang_questionnaire as a means of screening for_obstructive sleep apnea in adults in Brazil. Jornal Brasileiro de Pneumologia; 2017. 43(6): 456-463.

DOI : $10.1590 / \mathrm{S} 1806-37562017000000139$

25. Chung, F, Abdullah, HR, \& Liao, P. STOP-Bang Questionnaire. Chest; 2016. 149(3): 631-638.

DOI : 10.1378/chest.15-0903

26. International Diabetes Federation. The IDF consensus worldwide definition of the Metabolic Syndrome. Brussels, Belgium; 2006.

27. Tan GS, Wong TY, Fong CW \& Aung T. Diabetes, metabolic abnormalities, and glaucoma. Arch Ophthalmol; 2009. 127: 1354-1361.

DOI : 10.1001/archophthalmol.2009.268.

28. Klein BE, Klein R \& Jensen SC. Open-angle glaucoma and older-onset diabetes. The Beaver Dam Eye Study. Ophthalmology; 1994. 101: 1173-1177. DOI : 10.1016/s0161-6420(94)31191-2

29. Bonovas S, Filioussi K, Tsantes A \& Peponis V. Epidemiological association between cigarette smoking and primary open-angle glaucoma: a metaanalysis. Public Health; 2004. 118: 256-261.

DOI : $10.1016 /$ j.puhe.2003.09.009
30. Nakamura M, Kanamori A \& Negi A. Diabetes mellitus as a risk factor for glaucomatous optic neuropathy. Ophthalmologica; 2005. 219: 1-10.

DOI : 10.1159/000081775

31. Chopra V, Varma R, Francis BA, Wu J, Torres M \& Azen SP. Type 2 diabetes mellitus and the risk of open-angle glaucoma the Los Angeles Latino Eye Study. Ophthalmology; 2008. 115: 227-232e221. DOI : 10.1016/j.ophtha.2007.04.049.

32. Pasquale LR \& Kang JH. Lifestyle, nutrition, and glaucoma. J Glaucoma; 2009. 18: 423-428.

DOI : 10.1097/IJG.0b013e31818d3899

33. Newman-Casey PA, Talwar N, Nan B, Musch DC \& Stein JD. The relationship between components of metabolic syndrome and open-angle glaucoma. Ophthalmology; 2011. 118: 1318-1326.

DOI : 10.1016/j.ophtha.2010.11.022

34. Flammer J, Orqül S, Costa VP, Orzalesi N, Krieglstein GK, Serra LM, Renard JP \& Stefánsson E. The impact of ocular blood flow in glaucoma. Prog Retin Eye Res; 2002. 21: 359-393. DOI : 10.1016/s13509462(02)00008-3

35. Grieshaber MC \& Flammer J. Blood flow in glaucoma. Curr Opin Ophthalmol; 2005. 16: 79-83. DOI : 10.1097/01.icu.0000156134.38495.0b.

36. Suh MH, Park KH \& Kim DM. Effect of travoprost on intraocular pressure during 12 months of treatment for normal-tension glaucoma. Jpn J Ophthalmol; 2009. 53: 18-23. DOI : 10.1007/s10384-008-0617-8

37. Tielsch JM, Katz J, Sommer A, Quigley HA\& Javitt JC. Hypertension, perfusion pressure, and primary open-angle glaucoma. A population-based assessment. Arch Ophthalmol; 1995. 113: 216-221.

DOI : 10.1001/archopht.1995.01100020100038

38. Quigley HA, West SK, Rodriguez J, Munoz B, Klein $\mathrm{R} \&$ Snyder R. The prevalence of glaucoma in a population-based study of Hispanic subjects: Proyecto VER. Arch Ophthalmol; 2001. 119: 1819-1826.

DOI : 10.1001/archopht.119.12.1819

39. Gordon MO, Beiser JA, Brandt JD et al. The Ocular Hypertension Treatment Study: Baseline factors that predict the onset of primary open-angle glaucoma. Arch Ophthalmol; 2002. 120: 714-720.

DOI : 10.1001/archopht.120.6.714.

40. Shim SH, Kim JM, Woo HY, Shin KU, Koh JW, Park $\mathrm{KH}$. Association between platelet function and disc hemorrhage in patients with normal-tension K. Atalay et al./Medical Hypotheses 103 (2017) 54-56 55 glaucoma: A prospective cross-sectional study. Am J Ophthalmol; 2015. 160:1191-9. DOI : 10.1016/j.ajo.2015.09.006

41. Meyer JH, Brandi-Dohrn J, Funk J. Twenty four hour blood pressure monitoring in normal tension glaucoma. Br J Ophthalmol; 1996. 80:864-7. DOI : $10.1136 /$ bjo.80.10.864

42. Cartwright MJ, Grajewski AL, Friedberg ML, Anderson DR, Richards DW. Immune-related disease and normal-tension glaucoma: A case-control study. Arch Ophthalmol; 1992. 110:500-2.

DOI : 10.1001/archopht.1992.01080160078035

43. Sunbul M, Gerin F, Durmus E, et al. Neutrophil to lymphocyte and platelet tolymphocyte ratio in patients 
44. withdipper versus_non-dipper hypertension. Clin Exp Hypertens; 2014. 36:217-21. DOI : $10.3109 / 10641963.2013 .804547$

45. Kaya MG, Yarlioglues M, Gunebakmaz O, et al. Platelet activation andinflammatory response in patients with non-dipper hypertension. Atherosclerosis; 2010; 209:278-82.

DOI : 10.1016/j.atherosclerosis.2009.09.010

46. Fan N, Wang P, Tang L, Liu X. Ocular blood flow and normal tension glaucoma. Biomed Res Int; 2015. 2015:308505.

DOI : https://doi.org/10.1155/2015/308505

47. Galassi F, Giambene B, Varriale R. Systemic vascular dysregulation and retrobulbar hemodynamics in normal-tension glaucoma. Invest Ophthalmol Vis Sci; 2011. 52:4467-71.

DOI : https://doi.org/10.1167/iovs.10-6710

48. Danese E, Montagnana M, Lippi G. Platelets and migraine. Thromb Res; 2014. 134:17-22. DOI : 10.1016/j.thromres.2014.03.055

49. Karabulut KU, Egercioglu TU, Uyar M, Uçar Y. The change ofneutrophils/lymphocytes ratio in migraine attacks. Ann Med Surg; 2016. 10:52-6. DOI : 10.1016/j.amsu.2016.07.023.

50. Kremmer S, Kreuzfelder E, Klein R, et al. Antiphosphatidylserine antibodies areelevated in normal tension glaucoma. Clin Exp Immunol; 2001. 125:211-5. DOI : 10.1046/j.1365-2249.2001.01578.x

51. Maruyama I, Ikeda $Y$, Nakazawa $M$, Ohguro $H$. Clinical roles of serum autoantibody against neuronspecific enolase_in glaucoma patients. _Tohoku JExp Med; 2002. 197:125-32. DOI : 10.1016/s00215155(01)00455-5

52. Tezel G, Hernandez R, Wax MB. Immunostaining of heat shock proteins in the retina and optic nerve head of normal and glaucomatous eyes. Arch Ophthalmol; 2000. 118:511-8. DOI : 10.1001/archopht.118.4.511

53. Yang J, Tezel Gln, Patil RV, Romano C, Wax MB. Serum autoantibody against glutathione S-transferase in patients with glaucoma. Invest Ophthalmol Vis Sci; 2001. 42:1273-6. Avalaible from : https://pubmed.ncbi.nlm.nih.gov/11328739/

54. Romano C, Barrett DA, Li Z, Pestronk A, Wax MB. Anti-rhodopsin antibodies insera from patients with normal-pressure glaucoma. Invest Ophthalmol Vis Sci; 1995. 36:1968-75. Avalaible from : https://pubmed.ncbi.nlm.nih.gov/7657539/

55. Wax MB, Tezel G, Edward PD. Clinical and ocular histopathological findings in a patient with normalpressure glaucoma. Arch Ophthalmol; 1998. 116:9931001. DOI : 10.1001/archopht.116.8.993 